\title{
Antes e depois da razão: sobre a Filosofia Positiva de Schelling
}

\author{
Before and after reason: about the Positive Philosophy of Schelling
}

\author{
Rosalvo Schütz \\ rosalvoschutz@hotmail.com \\ (Universidade Estadual do Oeste do Paraná, Toledo, Brasil)
}

\begin{abstract}
Resumo: A chamada Filosofia Positiva de Schelling é resultado da suspeita desse autor em relação à filosofia enquanto identificada com princípios lógicos e racionais. Detectado o problema funda mental da filosofia puramente racionalSchelling sugere uma concepção de filosofia de tal forma abrangente que inclua também aquilo que vem antes e depois da razão, enquanto momentos constituintes da mesma. Com sua Filosofia Positiva pretende ter desenvolvido uma noção de filosofia capaz de tematizar 0 mundo de forma mais apropriada: aberta à admiração e ao processo histórico-natural do mundo. Para tanto teve de desenvolver também uma noção de verdade apropriada a esta concepção.
\end{abstract}

Palavras-chave: sistema; limite da razão; filosofia histórica; verdade.
Abstract: The Positive Philosophy of Schelling is the result of this author suspicion in relation to philosophy identified with logical and rational principles. Once the fundamental problem of the purely rational philosophy is detected, Schelling suggests a conception of philosophy in such a comprehensive manner that also includes what comes before and after reason as constituents of it at the same time. With his Positive Philosophy he claims to have developed a notion of philosophy able to thematize the world more appropriately: open to wonder and the natural-historical process of the world. Therefore, a notion of truth appropriate to this conception had to be developed.

Keywords: system; limits of reason; historical philosophy; truth.

DOI: http://dx.doi.org/10.11606/issn.2318-9800.v19i2p95-110

Introdução

O progressivo agravamento dos problemas ambientais e sociais em nível global parece estar evidenciando um crescente distanciamento/alienação em relação à natureza. A possibilidade de nos conceber- 
mos enquanto constituintes do mundo natural e vivo parece estar bloqueada, de modo que as fronteiras do pensamento filosófico dificilmente conseguem ultrapassar o pressuposto de uma natureza morta e à disposição da subjetividade. Quais seriam as origens da nossa impotência teórica e prática, a ponto de, apesar dos enormes avanços técnicos e científicos, não conseguirmos enfrentar alguns dos principais problemas que nos afligem, como é o caso daqueles relacionados à destruição ambiental? Talvez esta realidade seja algo constitutivo ou mesmo resultado da razão e da civilização na forma como foram configuradas na modernidade. Estaríamos, portanto, diante do desafio de rever estes horizontes e pressupostos. Na medida em que razão e civilização moderna são, em grande parte, resultado de um longo desenvolvimento histórico, muitas vezes perpassado por divergências e dissonâncias, a busca de concepções de razão e mesmo de filosofia que não tenham sido contempladas nas concepções atualmente hegemônicas, talvez possa contribuir para visualizar horizontes e perspectivas bloqueadas na atualidade e que nos subsidiem na formulação de perspectivas de superação.

Estamos convencidos de que Friedrich Schelling foi um desses pensadores. Suas reflexões, feitas no contexto do Idealismo Alemão - seja pela originalidade de sua Filosofia da Natureza ou pelo desenvolvimento de uma concepção de Filosofia Positiva que se pretende disposta a se deixar fecundar pela realidade viva sem reduzi-la a simples instrumento à disposição da subjetividade absoluta - por exemplo, nos parecem representar um marco dentro dessas dissonâncias. Acreditava que, dificilmente, conseguiríamos repensar a nossa relação com a natureza nos limites da filosofia como ela vinha sendo concebida até então. Sugere, então, um novo horizonte filosófico, por ele denominado de Filosofia Positiva. Para poder desenvolver esta concepção específica de Filosofia Positiva, fez um diagnóstico do que considerou um problema fundamental de todos os sistemas filosóficos modernos até então, a fim de superá-lo. Como veremos, esse limite fundamental consiste, segundo Schelling, no fato de os sistemas estarem reduzidos a pressupostos puramente lógico-causais, impossibilitando a tematização viva/histórica da realidade.

\section{Situando "as filosofias" de Schelling}

O pensamento de Friedrich Wilhelm Joseph Schelling (1775 1854) é, de modo geral, considerado (ao contrário do de seus con- 
temporâneos e também representantes do idealismo alemão, Fichte e Hegel) de forma descontínua, ou mesmo inacabada. Muitas vezes é dividido em fases que parecem se excluir mutuamente.

Assim, por exemplo, ao período inicial, concentrado em problemas da "filosofia transcendental", é contraposto um período da "filosofia da natureza". Ou à sua "filosofia da natureza" é contraposta à "filosofia da identidade", da "religião", da "mitologia", etc. Mesmo assim, porém, através da leitura dos textos do autor nos convencemos de que essas 'filosofias de Schelling' oferecem uma força compreensiva mais ou menos coerente, capaz não só de diagnosticar, a partir de perspectivas diferenciadas, fundamentos de muitos problemas modernos, mas também de apontar perspectivas de superação desses problemas. Concordamos, portanto, com a intuição de alguns de seus comentadores ${ }^{1}$ segundo os quais existe uma preocupação básica que perpassa todas as suas obras. Nesse sentido, os diferentes momentos de sua filosofia seriam apenas formas diferenciadas de abordar e de superar uma mesma problemática central e que tal problemática, de certa forma, já encontraria sua expressão originária em Kant. Como sabemos, segundo Kant, o ser humano é cidadão de dois mundos: um seria o reino da causalidade e da ciência, e o outro seria o da liberdade e da possibilidade da moral. Ou seja, o mundo fenomênico e o mundo noumênico. No primeiro desses mundos, o ser humano é objeto do conhecimento e, no segundo, sujeito de decisões morais. Na Crítica da Faculdade do Juizo, no entanto, Kant refere-se ao ser orgânico como sendo, embora natural, não compreensível e explicável por simples determinações causais. Kant aponta, assim, para uma perspectiva de superação desse dualismo ou, pelo menos, para indícios de uma unidade originária, ao abordar o ser orgânico ${ }^{2}$. Da superação desse dualismo entre liberdade e determinismo, entre espírito e natureza, entre ser e pensar, dessa temática Schelling fez a centralidade de sua atividade filosófica. Este nos parece ser o fio condutor de todas as fases de

1. Cf. BAUMGARTNER, H. M.; KORTEN, H. Friedrich Wilhelm Joseph Schelling. München: C. H. Beck'sche Verlagsbuchhandlung, 1996; FRANK, M.. Eine Einfübrung in Schellings Philosopbie. Frankfurt am Main: Suhrkamp, 1995; WETZ, F. J.. Friedrich W. J. Schelling zur Einfübrung. Hamburg: Junius Verlag, 1996; VIEIRA, L.. Schelling.Rio de Janeiro: Jorge Zahar, 2007 (Filosofia Passo a Passo, v. 74).

2. Cf. SCHÜTZ, R. A concepção multifacetada de natureza em Kant. Revista Véritas. Porto Alegre, v. 54, p. 238-256, 2009. 
sua filosofia. A filosofia de Schelling é toda ela engajada na busca da superação do distanciamento entre ser humano e natureza, distanciamento por vezes expresso também na forma de dualismos como espírito e matéria, necessidade e liberdade, natureza e sociedade.

Por isso, para entendermos a proposta da sua Filosofia Positiva, esta desenvolvida em sua maturidade, torna-se interessante lançar um olhar sobre o conjunto de sua obra. Buscaremos, assim, por um lado, apontar para o fio condutor que, na nossa avaliação, perpassa as diversas fases da filosofia schellinguiana, para, por fim, apontar para a problemática específica da sua Filosofia Positiva.

Em seu escrito, intitulado Ideias para uma Filosofia da Natureza, na Introdução ${ }^{3}$ escrita em 1797, Schelling expôs, de forma precisa, o alcance do referido distanciamento. Segundo o autor, existe um potencial destrutivo inerente à forma de ser do ser humano. A explicação que se dá para esse potencial estaria em que, por um lado, somos seres físicos, orgânicos e vivos, ou seja, seres naturais e, por outro lado, somos seres livres. As ações humanas podem, apesar de sua condição natural, libertar-se das determinações naturais e se orientar por fins previamente concebidos. Daí decorrem ações que, além de serem constituidoras do sentido da vida humana, são a expressão da própria liberdade. Por isso mesmo, por não ser mais totalmente determinado pela dinâmica natural, o ser humano pode, ao interferir na dinâmica da natureza, contrapor-se a ela e, com isso, contrapor-se às próprias condições vitais de sua existência.

Contribuir na elaboração de uma filosofia da natureza capaz de levar a sério a problemática da produtividade viva da natureza, e da autonomia dessa produtividade, na qual também o próprio ser humano e a sociedade pudessem ser compreendidos enquanto tais, pode ser considerado um dos maiores desafios/potenciais da filosofia de Schelling. Ou seja, trata-se de uma filosofia na qual não seja, de antemão, pressuposta uma separação entre ser humano/sociedade e natureza. Para se aproximar de forma mais adequada dessa tarefa, Schelling foi obrigado, no entanto, a desenvolver uma concepção própria de filosofia, uma vez que considerava que a concepção tradicional de filosofia não era capaz de fazê-lo.É essa concepção es-

3. SCHELLING, F. W. J. Einleitung in die Philosophie der Offengahrung oder Begründung der positiven Philosophie. Berliner Vorlesungen (1942/43). In: Ausgewäblte Scbriften. Band 05. Frankfurt am Main: Suhrkamp, 1985. 
pecífica que aqui nos interessa. Antes, porém, passou por outros momentos de elaboração.

Pelo menos três fases da filosofia de Schelling parecem tematizar de forma diferenciada a problemática levantada. Cada uma significa o amadurecimento e a "abertura de caminho" para outra fase, sem que, no entanto, as fases anteriores possam ser consideradas falsas. Dessa forma, mesmo em seus últimos escritos, Schelling não nega os primeiros, mas os pressupõe.

Naquilo que geralmente é considerado o primeiro momento de sua filosofia, caracterizado pela tematização da Filosofia Transcendental e da Filosofia da Natureza, Schelling procura abordar a produtividade da natureza enquanto autônoma, autoprodutiva, tematizando simultaneamente a liberdade e a determinação tendo em vista uma unidade originária de ambas. Já nessa fase Schelling intui que a pura reflexão como um fim em si mesmo é algo perigoso. Intui isso por perceber que uma reflexão desse tipo se orienta apenas por fins autopostos, de modo que há aí uma absolutização do eu e, por consequência, uma separação com sua base orgânica. A separação entre o fundamento orgânico/natural e a consciência deveria ser apenas um meio e, sempre que posta enquanto um fim, representaria a possibilidade de uma "doença": quando os pressupostos lógicos da razão se tornaram o pressuposto da unidade, ou seja, a crença de que a razão é o único princípio capaz de abarcar toda a realidade, tendencialmente há a afirmação de uma falsa unidade através da qual a razão é afirmada de forma absoluta em relação ao ser. Esta crítica também pode ser tomada como sendo uma reação especial ao pensamento de Fichte, no qual, como afirma Vieira " "[...] a natureza é um não-eน [...] um ser meramente objetivo, um puro não-eu, uma realidade oposta ao eu e, simultaneamente, posta à disposição dos interesses desse mesmo eu". O absolutismo da razão implicaria, portanto, a pretensão absolutista do eu. $\mathrm{O}$ ser humano artificialmente se sobrepõe à natureza. Como consequência, toda a natureza é reduzida a um não-ser (inclusive a própria corporeidade e a comunidade humana). Schelling quer superar esse dualismo apontando para uma possível unidade originária de ambos. Seu ponto de partida para pensar essa superação ora é a natureza, ora é a liberdade humana. Busca demonstrar que ambos os pontos de partida, que a princípio aparecem contraditórios, se mostram como complementares. Tanto do ponto de vista da filosofia da nature-

4. VIEIRA, L. Schelling. Rio de Janeiro: Jorge Zahar, 2007, p. 24. 
za quanto do da filosofia transcendental, o autor procura evidenciar a autonomia produtiva da natureza, apontando, também, que o próprio ser humano (espírito) é produto e partícipe da produtividade da natureza. Embora as duas formas de abordagem cheguem às mesmas conclusões, e embora Schelling já enfatize, especialmente na Introdução, que o vir-a-ser (natura naturanz) do mundo tem primazia sobre o que é (natura naturata), continuam, no entanto, existindo duas filosofias paralelas e Schelling não parece ter se dado por satisfeito com as soluções encontradas.

Num segundo momento, Schelling buscou, através da construção de um sistema absoluto da filosofia, superar a separação entre filosofia da natureza e transcendental. Depois da separação entre res cogitans e res extensa explicitadas pela filosofia cartesiana, a filosofia teria se tornada incapaz de pensar a vida. Ao "eu penso" Schelling contrapõe o "eu sou", apontando, assim, para uma produtividade não previamente determinável na qual o eu possa se autocompreender não apenas enquanto produto, mas também como atividade. Schelling pretende recuperar essa capacidade de tematizar a vida enquanto unidade originária entre essas duas substâncias. Essa fase é também chamada de "filosofia da identidade", por representar a tentativa de expor liberdade e necessidade, identificando ser e pensar em um mesmo sistema. Trata-se de uma procura pela unidade essencial entre ser humano e natureza, mediante uma exposição com pretensões de sistema correspondente à totalidade da realidade a fim de evitar a dualidade. Necessidade e liberdade aparecem como integrantes de um todo absoluto. A necessidade de identificar ser e pensar, dada como pressuposto de tal sistema, no entanto, parece ter deixado Schelling insatisfeito com esse sistema, obrigando-o a seguir para um momento seguinte.

O terceiro momento é, pois, o período da assim chamada Filosofia Positiva. Nesse período Schelling busca fundamentar uma filosofia que, sem abrir mão da noção de sistema, pretende também estar aberta ao inusitado histórico e contribuir com algo mais do que com a expansão quantitativa do conhecimento. Buscava ele uma forma de filosofar que não se limitasse a critérios puramente racionais, mas que aceitasse ao mesmo tempo a religião, a arte, a mitologia e a sensibilidade enquanto manifestações autônomas e vivas, enquanto possíveis impulsos originais do filosofar. Ser e pensar são concebidos a partir de suas especificidades e imbricações mútuas, no entanto, há uma primazia do ser em relação ao pensar, uma vez que nenhum sistema poderá mais 
se apresentar como sendo uma explicação última e absoluta da realidade. Ao contrário da filosofia puramente lógica, sistemática, a qual Schelling passa a chamar de Filosofia Negativa (incluindo aí a sua própria filosofia desenvolvida até então), esta nova seria uma Filosofia Positiva. É a tentativa de superar uma filosofia puramente racional (reinrationale Pbilosophie), também denominada de filosofia lógica (logische Pbilosopbie), a fim de tematizar a realidade de forma mais acertada (die richtige Wirklichkeit). Além de Positiva, o autor também chama esta de Filosofia Histórica (geschichtliche Pbilosophie).

A Filosofia Positiva de Schelling tem em comum com as outras fases o fato de se preocupar em buscar superar a dualidade entre natureza e espírito herdados da tradição. Sua especificidade é que procura desenvolver uma concepção de filosofia apropriada para tal, uma vez que considerava a concepção predominante no contexto moderno incapaz de realizar essa tarefa. Neste texto, por isso, nos delimitamos à tentativa de reconstruir e apropriar aquilo que o próprio Schelling apontou como sendo o problema filosófico específico a ser superado nessa fase no âmbito da própria concepção de filosofia. Como os livros Filosofia da Mitologia e Filosofia da Revelação já são "exercícios filosóficos" dessa terceira postura, não serão abordados aqui. Tomaremos como base algumas observações de Schelling na primeira parte de suas preleções de Munique ${ }^{5}$ de 1832 (Grundlegungderpositiven Pbilosopbie) e de Berlin ${ }^{6}$ em 1842 (Einleitung in die Pbilosopbie der Offenbabrung oder Begriundung der positiven Pbilosopbie). Em ambas Schelling pretende oferecer uma espécie de introdução à Filosofia Positiva, privilegiando, assim, a identificação e os delineamentos básicos de tal filosofia. Buscaremos perceber duas questões que parecem orientar as reflexões: 1) Porque a filosofia até então é considerada insuficiente? 2) De quais características a Filosofia Positiva não pode prescindir?

\section{O equívoco fundamental dos sistemas da filosofia moderna}

Nas preleções de Munique, que pretendem ser uma introdução à Filosofia Positiva, Schelling inicia sua reflexão afirmando que,para

5. SCHELLING, F. W. J. Grundlegungderpositiven Pbilosopbie: Münchener Vorlesung WS 1832/33 und SS 1833 (I.Teil). Torino: Botteg d'Erasimo, 1972.

6. SCHELLING, F. W. J. Einleitung in die Philosophie der Offengahrung oder Begründung der positiven Philosophie. Berliner Vorlesungen (1942/43). In: Ausgewäblte Schriften. Band 05. 
entendermos algo em filosofia, geralmente são pressupostos alguns conhecimentos prévios em relação a ela. Ou seja, a compreensão sobre assuntos determinados da filosofia geralmente é marcada por noções e conhecimentos que já temos até então. Consequentemente, a compreensão do que seja filosofia pode variar muito de indivíduo para indivíduo. O que Schelling ${ }^{7}$ questiona então é se, mesmo assim, seja possível lançar a pergunta em torno do que "é a filosofia ela mesma?" ${ }^{\prime \prime}$. Em princípio, esta parece ser uma pergunta para a qual dificilmente podemos esperar uma resposta, uma vez que cada pessoa a define marcada pela sua visão prévia, além de que o próprio conceito de filosofia parece pressupor o fato de que já se tenha filosofado.

Schelling ${ }^{9}$ sugere então que se modifique a pergunta orientadora: "Nós, portanto, não queremos colocar a questão 'o que é filosofia?', mas, o que espera cada qual que vem a ela?" Segundo o autor, diferentemente das disciplinas diretamente aplicáveis (como direito e medicina), em filosofia parecemos esperar uma "força formativa/educativa genérica" (allgemeinbildende Kraft), que nos capacite diante de todas as relações e que parece imprescindível para formar pessoas realmente livres. Por outro lado, a filosofia tem causado muitas decepções quanto a essas esperanças, especialmente entre os jovens. Segundo Schelling, muitos jovens se aproximam da filosofia confiantes de que ela os ajudará a afastar o véu que parece encobrir a "incompreensível totalidade". Esperam encontrar aí "[...] convicções, sem as quais a própria vida não parece ter finalidade"110. A juventude parece pedir uma "verdade orientadora da vida" e espera da filosofia uma orientação para tal. É uma esperança que parece legítima, em se considerando a diferença da filosofia em relação às outras ciências. O desafio, portanto, seria conceber a filosofia de tal forma que ela possa fazer jus a essa esperança que a juventude nela deposita.

Contribuir para que as pessoas se apropriem de tal "verdade orientadora da vida" não parece uma tarefa nada fácil, principalmente pelo fato de que "[...] não existe uma verdade única ou isolada"11. Uma

7. SCHELLING, F. W. J. Grundlegungderpositiven Philosophie: Münchener Vorlesung WS 1832/33 und SS 1833 (I.Teil), p. 67.

8. Todas as traduções de citações foram feitas pelo autor desse texto.

9. Idem, p. 68.

10. Idem, p. 69.

11. Idem, ibidem. 
verdade assim concebida parece existir apenas em Deus, e o ser humano, portanto, apenas pode aspirar a ela. Além disso, de fato, nenhuma ciência particular pode pretender conter essa verdade, embora possa sobre ela conter certas reflexões. A filosofia, portanto, não pode nem mesmo substituir a religião no que diz respeito a sugerir um acesso direto à verdade, nem querer sugerir uma verdade última a partir de alguma afirmação ou sistema particular, embora também não possa abrir mão de sugerir um horizonte de verdade mais amplo do que as ciências particulares. Disso Schelling conclui que a filosofia é uma espécie de "[...] busca de conhecimento das inter-relações gerais, e ela aspira necessariamente e conforme sua natureza ao sistema $[\ldots]^{\prime \prime 2}$. Ou seja, como o acesso direto a uma verdade única ou isolada não é possível, a filosofia se vê diante do desafio de (re)construir de forma sistemática uma perspectiva capaz de dar conta daquilo que dela se espera, daí sua inevitável proximidade com um sistema.

Aproximar filosofia com sistema, no entanto, poderia causar certo mal-estar, isso porque geralmente identificamos sistema com uma teoria unilateral, fechada em si mesma. Schelling, por isso, se adianta em dizer o que não deveríamos entender por sistema num horizonte filosófico. Não deveríamos identificar sistema com uma teoria unilateral (einseitige Theorie). Exemplos, onde sistema pode ser tomado como sendo uma postura unilateral, seriam um médico que tudo enquadra em seu sistema específico ou um "homem de Estado" que se torna insensível diante dos reais problemas da população orientando-se exclusivamente por uma teoria previamente concebida. Ou seja, sempre que alguém pretende impor um sistema parcial ao todo. Segundo Schelling, tal postura é sempre desprezível e, de modo especial, na filosofia. Isso, no entanto, não depõe contra a possibilidade de sistema no sentido de se buscar entender o "contexto geral" (allgemeine Zusammenhang) que parece existir objetivamente e independente de nós.

A questão, no entanto, é saber se "[...] o espírito humano é capaz de se apropriar de tal contexto geral"13. A questão se agrava ainda mais diante do fato de que a experiência tem mostrado a "[...] transitoriedade de todos os sistemas enquanto tais" ${ }^{\prime 14}$. Ou seja, a filosofia parece

\footnotetext{
12. Idem, p. 70.

13. Idem, p. 73 .

14. Idem, Ibidem.
} 
estar diante de um impasse: ela não pode prescindir do sistema, tem de ser cuidadosa para não impor um sistema parcial ao todo, mas também não parece capaz de edificar um sistema que de fato represente o todo. Seria preciso, pois, desenvolver uma concepção adequada de sistema que permitisse que a filosofia apontasse para algum sentido sem se tornar dogmática/fechada.

Entender o que os sistemas filosóficos desenvolvidos até então têm em comum, isso talvez indique para o que o sistema não pode ser. Ou seja: talvez todos os sistemas tenham algo em comum, e aquilo que tenham em comum talvez seja o "o erro básico" de todos. A questão colocada por Schelling ${ }^{15}$, portanto, é: "Qual é o caráter comum de todos os mais recentes sistemas desde Descartes?". Sem delongas aponta para aquilo que julga ser o equivoco básico: "[...] o caráter comum de todos estes sistemas é o caráter somente lógico, ou, de que neles são procuradas apenas relações lógicas" ${ }^{\prime \prime}$.

O sistema proposto por Spinoza serve de protótipo para demonstrar esse caráter. Trata-se de um sistema que, segundo Schelling, tem uma grande atratividade/encantamento pelo fato de que aceita e pressupõe uma "inter-relação objetiva" abrangente e global do mundo de modo a, aparentemente, satisfazer a exigência de oferecer um sentido para a vida e afastar o véu encobridor da realidade. Tal sistema, no entanto, não dá conta de sua promessa e não dá conta por condenar tudo e todos a um determinismo puramente lógico. Segundo Schelling ${ }^{17}$, para Spinoza, " $[\ldots]$ entre Deus, enquanto mais alta substância, e as coisas, não há outra inter-relação a não ser a lógica. As coisas são apenas emanações lógicas do ser divino, que advém do mesmo de uma forma eterna".De fato, apesar de Spinoza ter expressado isso de forma logicamente coerente, ele, no entanto, não o demonstrou. Simplesmente sugere que o aceitemos. Isso, no entanto, para Schelling, não corresponde à realidade. Quando, por exemplo, alguém crente afirma que Deus criou livremente o mundo e todas as coisas, não há aí nenhuma relação lógica pressuposta: "Aqui é pressuposto um ato real, um fato, é afirmada uma consequência, uma relação histórica"18. Em Spinoza, as coisas decorrem de Deus sem ação alguma

\footnotetext{
15. Idem, p. 74 .

16. Idem p. 75 .

17. Idem, Ibidem.

18. Idem, Ibidem.
} 
deste, o que expressa uma negação de toda a forma de ato, de modo que,"[...] conforme Spinoza, Deus é a causa de todas as coisas por meio de sua própria natureza"19.

Assim, ao tematizar a concepção de sistema inerente à teoria de Spinoza, Schelling conclui que, por meio dos sistemas, "[...] nos quais na realidade nada acontece, nos quais, portanto, não se experiencia nada, pode até ser expandido o nosso pensar $-[\ldots]_{;}$mas o nosso saber, o que nós denominamos saber propriamente dito, não é expandido de forma alguma" ${ }^{\prime 20}$. Concluindo, afirma que o equívoco fundamental de todos os sistemas desde Descartes, seja Deus neles compreendido como resultado ou como fim, consiste no fato de pressuporem que Deus tem apenas uma relação lógica com o mundo. Ou seja: todos são não-históricos, não admitem o agir livremente, a introdução do novo no mundo, a inevitável irrupção do previamente indeterminável. Nisso consistiria o limite básico da concepção de sistema, limite esse que, na medida em que está na base da concepção filosófica, aponta para a mudança necessária na filosofia: "[...] a verdadeira reforma da filosofia seria esta que, no lugar de um sistema não histórico, seja capaz de erigir um sistema verdadeiramente histórico" ${ }^{\prime 21}$.

Esse desafio básico sugerido por Schelling para a filosofia pode ser percebido também nas preleções de Berlin, oferecidas 10 anos depois (1842) de suas preleções de Munique. Nelas, no entanto, parece que a contraposição argumentativa não é mais tanto Spinoza quanto Hegel. Desse modo, pode-se afirmar, sem grandes reservas, que a crítica à filosofia hegeliana pode ser considerada uma das preocupações centrais do pensamento tardio de Schelling. Hegel teria radicalizado uma postura já perceptível em alguns aspectos da filosofia de Kant na medida em que esse, em termos de ciência, reduziu a razão (Vernunf) a um puro racionalismo (Rationalismus) "[...] e simplesmente expandiu e aceitou tacitamente o que tinha demonstrado apenas com relação à razão para toda a filosofia" ${ }^{\prime 22}$. A radicalização desse aspecto herdado da postura de Kant teria levado Hegel a come-

19. Idem, p. 79.

20. Idem, p. 80 .

21. Idem, Ibidem.

22. SCHELLING, F. W. J. Einleitung in die Philosophie der Offengahrung oder Begründung der positiven Philosophie. Berliner Vorlesungen (1942/43). In: Ausgewäblte Schriften. Band 05, p. 685. 
ter um equívoco básico, qual seja, o de equiparar ser e pensar.Essa tendência estaria constatável, especialmente, na identificação entre ser e pensar, geralmente operada à custa da autonomia do ser. Em contraposição a essa postura, Schelling sugere que deveríamos partir do pressuposto de que existe um ser absolutamente independente do pensar e no qual se fundaria toda a vitalidade filosófica e dialética. Essa necessidade de pensar para além de uma filosofia puramente racional seria totalmente desconhecida pela filosofia hegeliana.

Ao contrário de Hegel, que fez da equiparação entre realidade e racionalidade um princípio orientador da filosofia (chegando mesmo a "aprisionar' o ser dentro do conceito"), para Schelling a "[...]razão entende (begreift) o real, mas não a realidade. E isto é uma grande diferença" ${ }^{\prime 23}$. Tal postura diferenciada em relação a Hegel seria fundamental a fim de aceitar que também as experiências (aquilo que não foi previamente pensado ou não é previamente enquadrável em um princípio) tem importância para a filosofia. As experiências representariam uma espécie de instância de controle a fim de que a filosofia não se perca em quimeras e para o reconhecimento autêntico da alteridade do mundo e do outros:"Apenas pela experiência (ou seja, pela pura autoridade de nossos sentidos, e não por meio da razão) nós sabemos que existem coisas fora de nós" 24 . Há, pois, em Schelling uma primazia do ser em relação ao pensar: há algo anterior à razão de que a filosofia não pode prescindir. O grande mérito de Hegel seria o fato de ter demonstrado que todo o conhecimento deve fazer referência a um todo, mas o erro fundamental residiria em sua pretensão de fazer de sua filosofia um sistema de explicação positivo da realidade, tornando-a a-histórica, apesar de sua aparente valorização da história.Hegel teria, pois, inviabilizado a tematização de qualquer aspecto da realidade que não se deixe subsumir pelo princípio explicativo previamente estabelecido.

\section{Pressupostos de uma Filosofia Positiva}

Os sistemas baseados em pressupostos puramente lógicos, mesmo depois de compreendidos, segundo Schelling, nos deixam totalmente indiferentes e não contribuem, por isso, para qualificar nossa sabedoria. Eles, portanto, deporiam contra o impulso original da filo-

23. Idem, p. 663.

24. Idem p. 774. 
sofia, que, desde Platão, é identificado com a admiração (Bewunderung): "Apenas um fato oriundo de uma vontade não compreensível (unbegreiflichen Willen) pode trazer à tona a admiração"25. Se, porém, por outro lado, como vimos acima, não se pode prescindir de certa esperança de sistema, como conciliar sistema com admiração, enquanto impulso básico para o filosofar? Ora, segundo nosso autor, isso significa que "[...] tal sistema deve ser mais do que simples racionalismo, que ele deve conter algumas pistas sobre as grandes questões, que, no entanto, devem ser alcançadas internamente por um processo verdadeiramente imanente e filosófico ${ }^{\prime 26}$. Diante dessas reflexões é sugerido que tal filosofia, em contraposição à desenvolvida até então pela filosofia moderna, passe a se chamar de Filosofia Positiva: "Caso se denomine de 'positivo' tudo onde decide uma vontade expressa, assim todos os sistemas que esclarecem tudo apenas por meio de inter-relações lógicas e nos quais falta o ato positivo, devem ser chamados de negativos, e, em contraposição a estes sistemas, ser declarados de positivos todos aqueles que contêm personalidade, vontade e ação" ${ }^{\prime 27}$. Essa filosofia também poderia ser denominada de histórica: "Filosofia histórica é aquela que esclarece o mundo a partir da liberdade, da vontade e da ação e, por isso,não a partir de emanações puramente lógicas de um princípio qualquer ${ }^{\prime \prime 28}$.Schelling, nesse ponto, faz questão de enfatizar que a própria natureza está incluída naquilo que compreende por mundo.

O interessante é que, dessa forma, Schelling engendra uma concepção de filosofia na qual está legitimada a tematização de todas as expressões da realidade, sejam elas naturais, religiosas, mitológicas, artísticas, etc. Ou seja, aceita e reconhece que há algo anterior à razão que é constitutivo para a filosofia. Simultaneamente, ele também não exclui como totalmente falso nenhum sistema filosófico, uma vez que eles não seriam falsos, mas apenas insuficientes. Eles apenas seriam falsos na medida em que se pretendem uma explicação última da realidade: "De fato a falsidade consiste apenas na direção exclusiva"29.

25. SCHELLING, F. W. J. Grundlegungderpositiven Pbilosopbie: Münchener Vorlesung WS 1832/33 und SS 1833 (I.Teil), p. 82.

26. Idem, p. 83 .

27. Idem, Ibidem.

28. Idem, p. 84.

29. Idem, Ibidem. 
Dessa forma, Schelling não pretende que apenas a Filosofia Positiva seja considerada verdadeira em contraposição à Negativa. Aponta apenas para o limite e para os perigos de ela cair em falsidade na medida em que se pretende um sistema último ou abrangente de explicação da realidade a partir de um princípio específico. Ao afirmar que sistemas filosóficos deveriam "ser mais do que simples racionalismo", explicita também a necessidade de a filosofia ir para além da razão.

É evidente que tal concepção de filosofia não se contenta mais com a tarefa que a metáfora da coruja lhes sugere, de muita sabedoria acumulada, mas que somente aparece (voa) tardiamente, depois que o dia já acabou. Em vez de ser uma filosofia que se contente em apenas descrever o passado e o presente como fatos dados, ela os compreende inseridos em um processo histórico onde podem, inclusive, ser ressignificados, ou seja, "re-significados": "Na medida em que o presente já contém em si os germens do futuro, ele não pode ser conhecido sem o futuro" ${ }^{130}$. Uma filosofia, portanto, que não conseguiria tematizar o futuro, ou seja, que estivesse indiferente às possibilidades de futuro inscritas no presente seria, evidentemente, uma filosofia parcial, pois, por não conseguir tematizar aquilo que ainda não é, mas que pode ser, deixaria de tematizar grande parte da realidade. E essa inter-relação histórica não pode, segundo Schelling, ser confundida com uma simples explicação sucessiva de fatos, pois isso também seria possível em um sistema puramente lógico-objetivo (como em Spinoza). Explica que, nesse caso, não se precisaria pressupor realmente um ato. Schelling, por isso, diverge dessa postura e afirma: "A conexão entre A e B deve ser mediada por um efetivo acontecer. Uma tal conexão, portanto, não se deixa pensar sem um efetivo antes e depois ${ }^{1 / 31}$. Sem o pulsar vivo da história e do tempo, portanto, a filosofia também não pode manter efetivamente a sua vivacidade.

Por fim, para efetivarmos tal concepção de filosofia, é aconselhável, segundo Schelling, que nos libertemos de uma concepção de verdade perene. A verdade, que, por um lado, não é de forma alguma relativista e puramente subjetiva, por outro lado, deveria ser concebida enquanto uma posição compreensiva alcançada no interior de um processo histórico efetivo, do qual o próprio pensar e filosofar são constitutivos:"Nós, portanto, começamos a compreender que as assim

30. Idem, p. 85 .

31. Idem, p. 87. 
chamadas verdades eternas não são nada mais do que sentenças que abstraem o estado presente das coisas. Não existem verdades eternas neste sentido"32. Há de se entender, pois, que o próprio mundo (nós enquanto sujeitos filosofantes nele inseridos) ainda está em processo de (auto)criação. Assim, então, o vir-a-ser do mundo tem primazia sobre o ser. Ou, nas palavras de Schelling: "Todo passado e todo o futuro no mundo é sempre um relativo, sempre um vir-a-ser (werdende), nunca algo que já é (seiende) ${ }^{\prime \prime 3}$.

\section{Desafio para uma nova postura filosófica}

A proposta de Filosofia Positiva de Schelling tem o objetivo fundamental da superação de uma concepção de filosofia demasiadamente apegada ao caráter lógico-causal. Mesmo assim, porém, ela não se contrapõe de forma absoluta à filosofia puramente racional. O momento racional da filosofia não é desprezado. Sugere apenas que, para continuar coerente com a admiração enquanto impulso básico, a filosofia não pode prescindir da historicidade e, por isso, do vir-a-ser do mundo. Há algo que precede a razão e do qual a filosofia não pode prescindir. Ela não pode jamais se deixar aprisionar por um sistema prévio sob risco de perder sua própria vitalidade. O esforço de (re)construção sistemática da realidade, no entanto, também é imprescindível. É ele que possibilita indicar um sentido, contribuir para que os sujeitos possam se mover de forma mais autônoma no mundo. Esta é uma contribuição para a constituição de sentidos que levam inegavelmente para além da realidade científico-racional e sem a qual esses sentidos são facilmente instrumentalizados por uma racionalidade cega. A filosofia, portanto, também não deveria prescindir daquilo que vai para além da dimensão racional.

Se as perspectivas desenvolvidas por Schelling a partir daí, e apresentadas, por exemplo, na Filosofia da Revelação ou na Filosofia da Mitologia, são soluções satisfatórias para o desafio colocado não é uma questão que vem ao caso agora. Importa que a problemática explicitada parece dialogar diretamente com algumas ansiedades contemporâneas referidas na introdução deste trabalho. Uma filosofia assim concebida talvez esteja mais próxima de poder tematizar questões ambientais e sociais hoje simplesmente excluídas do horizonte temá-

32. Idem, p. 90.

33. Idem, p. 91. 
tico da filosofia. O desafio filosófico suscitado por Schelling, mesmo que no contexto do idealismo, certamente possui uma potencialidade reflexiva ímpar também na atualidade e sua atualização talvez seja um grande desafio.

Evidentemente não precisamos nos ater às soluções da questão apresentadas pelo próprio Schelling. Ou seja, talvez compreender a problemática pela qual Schelling se sentiu afetado já seja um subsídio importante a fim de podermos visualizar perspectivas próprias e inusitadas na filosofia e no mundo sem deixar de estar nele.

\section{Referências}

BAUMGARTNER, H. M.; KORTEN, H. Friedrich Wilhelm Joseph Schelling. München: C. H. Beck'sche Verlagsbuchhandlung, 1996.

FRANK, M. Eine Einfübrung in Schellings Philosopbie. Frankfurt am Main: Suhrkamp, 1995.

SCHELLING, F. W. J. Grundlegungderpositiven Pbilosopbie: Münchener Vorlesung WS 1832/33 und SS 1833 (I.Teil). Torino: Botteg d'Erasimo, 1972.

Einleitung in die Philosophie der Offengahrung oder Begründung der positiven Philosophie. Berliner Vorlesungen (1942/43). In: Ausgewäblte Scbriften. Band 05. Frankfurt am Main: Suhrkamp, 1985.

Einleitung zu: Ideen zu einer Philosophie der Natur als Einleitung in das Studium dieser Wissenschaft (1897). In: Ausgewäblte Scbriften. Band 01. Frankfurt am Main: Suhrkamp, 1985.

SCHÜTZ, R. A concepção multifacetada de natureza em Kant. Revista Véritas. Porto Alegre, v. 54, p. 238-256, 2009.

Sensibilidade emancipatória: Schelling, Feuerbach e Marx à contrapelo da tradição. In: CHAGAS, E.; REDYSON, D.; DE PAULA, M. (Orgs.). Homem e natureza em Ludwig Feuerbach. Fortaleza: Edições UFC, 2009b. v. 8, p. 171-212.

WETZ, F. J. Friedrich W. J. Schelling zur Einfübrung. Hamburg: Junius Verlag, 1996.

VIEIRA, L. Schelling. Rio de Janeiro: Jorge Zahar, 2007 (Filosofia Passo a Passo, v. 74). 